\title{
Atuação pública e privada na gestão de Unidades de Conservação: aspectos socioeconômicos da prestação de serviços de apoio à visitação em parques nacionais
}

\section{Public and Private Policy in the Management of Protected Areas: Socioeconomic Aspects in the Rendering of Support Services to Visitors in National Parks}

\author{
Camila Gonçalves de Oliveira RODRIGUES* \\ Larissa Ribeiro da Cruz GODOY**
}

\begin{abstract}
RESUMO
A necessidade de ofertar serviços de apoio à visitação em parques nacionais tem motivado a consolidação de instrumentos de gestão que propiciem a participação de diversos atores no desenvolvimento do turismo, tais como empresas, organizações da sociedade civil, associações e cooperativas de base comunitária. Este artigo visa apontar e discutir, com base em uma revisão teórico-conceitual, alguns dos principais aspectos socioeconômicos associados à prestação de serviços de apoio à visitação em parques nacionais. Dentre esses aspectos, destacam-se o incremento de recursos financeiros para a manutenção dos parques, o equilíbrio econômico-financeiro dos contratos firmados pelo poder público com particulares, a adequação e a qualidade dos serviços prestados e o potencial efeito dinamizador da economia tendente a favorecer o desenvolvimento socioeconômico local. A análise desses aspectos se baseou no levantamento bibliográfico e de dados secundários sobre a gestão de unidades de conservação e na análise de instrumentos normativos à luz da doutrina do direito administrativo. Uma das principais reflexões do artigo aponta que o aporte de recursos humanos e financeiros por parte das organizações pública e privada na gestão dos parques nacionais requer uma abordagem criteriosa, considerando as funções e responsabilidades no âmbito da gestão dessas áreas. Dessa forma, a convivência entre os regimes público e privado no mesmo espaço, como é o caso da prestação de serviços de apoio à visitação em unidades de conservação, requer o equilíbrio entre os resultados econômico-financeiros privados e os objetivos da função pública relativos à conservação da área e à democratização do seu acesso.
\end{abstract}

Palavras-chave: parques nacionais; visitação; esferas pública e privada.

\footnotetext{
" Doutora em Desenvolvimento Sustentável (Universidade de Brasília - UnB). Professora e Pesquisadora do Departamento de Administração e Turismo, do Programa de Pós-Graduação em Práticas em Desenvolvimento Sustentável e do Programa de Pós-Graduação em Desenvolvimento Territorial e Políticas Públicas da Universidade Federal Rural do Rio de Janeiro (UFRRJ).E-mail: camirodrigues@ufrrj.br

"* Mestranda em Direito e Política Públicas (Centro Universitário de Brasília - UniCEUB), Especialista em MBA - Gestão Ambiental em Cidades (Universidade Católica de Brasília - UCB), Analista Ambiental do Ministério do Meio Ambiente (MMA).E-mail: larissa.godoy@mma.gov.br
} 


\begin{abstract}
The need to offer support services to visitation in national parks has stimulated the consolidation of management tools which allow the participation of several actors in the process, such as the private initiative, organizations of civil society and local populations. This article aims at pointing out and discussing some of the key socioeconomic aspects associated with the rendering of support services to visitation in national parks. In particular, we highlight the increase of financial resources for park maintenance, the economic-financial balance of the contracts made between the public power and private third parties, the adequacy and quality of the services rendered and the potential dynamical effect of the economy to improve local socioeconomic development. The analysis relied on literature review and secondary data of the management of the conservation units and on the analysis of normative tools in the light of the doctrine of administrative law. One of the main considerations of the article points out that the investment of human and financial resources on the part of public and private organizations in the management of national parks requires a careful approach, considering the roles and responsibilities in the management of these areas. Therefore, the coexistence between public and private spheres in the same space, as it is the case of the rendering of services in conservation units, requires the balance between the private economic-financial outcomes and the aims of the public role in regard to the conservation of the area and the democratization of its access.
\end{abstract}

Keywords: national parks; visitation; public and private spheres.

\section{Introdução}

Os parques nacionais, além da função precípua de conservação da diversidade biológica, têm também por objetivo promover a visitação, com fins de educação e interpretação ambiental, recreação e turismo em contato com a natureza (BRASIL, 2000). Para que isso ocorra, é necessário estruturar os serviços de apoio às atividades de visitação ${ }^{1}$ a serem realizadas em áreas naturais públicas. A prestação desses serviços pode se dar de maneira direta, quando é fornecida pelo próprio Estado, ou indireta, quando o Estado os delega a particulares, por meio de instrumentos jurídicos específicos.

A necessidade de ofertar serviços de apoio à visitação em parques nacionais tem motivado a elaboração de instrumentos de gestão dessas unidades de conservação que propiciem a participação de diversos atores públicos e privados, tais como empresas, organizações da sociedade civil, associações e cooperativas de base comunitária.

Nesse contexto, a relação entre a fruição de um bem público, o parque nacional, e a exploração turística é me- diada pela prestação de serviços por entidades alheias ao serviço público. Essa dinâmica tende a impulsionar a apropriação mercadológica desse bem público, em diversas escalas, e a valoração econômica dos parques nacionais.

Esse artigo visa apontar e discutir, com base em uma revisão teórico-conceitual, alguns dos principais aspectos socioeconômicos associados à prestação de serviços de apoio à visitação em parques nacionais, tais como o acréscimo de recursos financeiros para a manutenção destas áreas, o equilíbrio econômico-financeiro dos contratos firmados pelo poder público com particulares, a adequação e a qualidade dos serviços prestados e o potencial efeito dinamizador da economia tendente a favorecer o desenvolvimento socioeconômico local.

\section{A exploração de bens e serviços nas unidades de conservação}

De acordo com o art. 33 da Lei 9.985, de 18 de julho de 2000, que instituiu o Sistema Nacional de Uni-

\footnotetext{
${ }^{1} \mathrm{O}$ termo visitação é utilizado com frequência nos documentos de planejamento e gestão de unidades de conservação para caracterizar o uso público nestas áreas. O uso público, por sua vez, pode ser entendido como uma forma de utilização das unidades de conservação, por meio da visitação, independentemente da motivação (lazer, contemplação, educação ambiental, esporte, observação de aves, entre outros) ou do segmento do turismo em questão (ecoturismo, turismo de aventura, entre outros) (RODRIGUES, 2009).
} 
dades de Conservação da Natureza-SNUC, no qual se inserem os parques nacionais, a exploração comercial de produtos ou serviços obtidos ou desenvolvidos a partir dos recursos naturais, biológicos, cênicos ou culturais, ou a exploração da imagem de uma unidade de conservação, dependerá de prévia autorização e sujeitará o explorador da atividade a pagamento, conforme previsto em regulamento.

O Decreto $n^{\circ} 4.340$, de 22 de agosto de 2002, que regulamenta a citada lei, dedicou o Capítulo VII ao tema da autorização para a exploração de bens e serviços em unidades de conservação. $\mathrm{O}$ art. 25 dessa norma dispõe que "é passível de autorização a exploração de produtos, subprodutos ou serviços inerentes às unidades de conservação, de acordo com os objetivos de cada categoria de unidade".

Os produtos e serviços relativos às unidades de conservação que são objeto de análise nesse artigo estão discriminados no inciso I do parágrafo único do mesmo art. 25, ou seja, "aqueles destinados a dar suporte físico e logístico à implementação das atividades de uso comum do público, tais como visitação, recreação e turismo".

Deve-se considerar que a exploração de bens e serviços realizados por terceiros em, ou a partir de, um parque nacional, depende de uma decisão prévia do órgão gestor da unidade, que poderá autorizá-la ou não, sendo que tais atividades devem estar previstas nos planos de manejo da unidade de conservação (art. 26 do Decreto 4.340/2002).

A transferência de certos serviços a terceiros pelo Poder Público tem sido defendida como uma forma de potencializar, de maneira sustentável, o aproveitamento dos recursos da unidade de conservação. Ao mesmo tempo, a desoneração dos órgãos estatais da prestação de alguns serviços - como os de apoio à visitação - nas unidades de conservação pode canalizar esforços para a realização de atividades como controle, monitoramento, fiscalização e proteção dos recursos naturais. Essas sim seriam atividades típicas a serem exercidas necessariamente por servidores públicos responsáveis pela gestão da unidade (ROCKTAESCHEL, 2006; RODRIGUES, 2009).

Ainda que os serviços de apoio à visitação nos parques nacionais não sejam considerados serviços públicos, em sentido estrito, a aplicação subsidiária da legislação relacionada à prestação desses serviços (Lei 8.987, de 1995, conhecida como a Lei das Concessões, por exemplo) orienta, em certa medida, o seu desenvolvimento em áreas de domínio público.

A escolha da forma da prestação de serviços públicos se insere no âmbito discricionário do Poder Público. No entanto, independentemente do arranjo institucional escolhido, a prestação de serviços deve observar os princípios básicos que caracterizam o chamado serviço adequado, definidos na Lei das Concessões: regularidade, continuidade, eficiência, segurança, atualidade, generalidade, cortesia na sua prestação, modicidade das tarifas.

Esses princípios conferem coesão e lógica ao sistema jurídico-administrativo e funcionam como as proposições básicas deste sistema (FURTADO, 2007). No que tange à prestação de serviços de apoio à visitação, esses princípios devem ser observados, com vistas ao seu desenvolvimento adequado e responsável nos parques nacionais.

As propostas de descentralização, desestatização, terceirização, características da reforma administrativa gerencial dos anos de 1990, influenciaram diversas políticas públicas, inclusive na área ambiental. Em 1999, o Instituto Brasileiro dos Recursos Naturais Renováveis - IBAMA, então responsável pela gestão das unidades de conservação federais, publicou o documento Marco conceitual e diretrizes para terceirizações administrativas em unidades de conservação (IBAMA/GTZ, 1999). A terceirização dos serviços, da maneira como foi proposta no documento, refere-se à prestação de serviços de forma descentralizada e de execução indireta, prevista por meio das seguintes modalidades: concessão, permissão e autorização.

Os instrumentos legais que regem essas modalidades e que orientam a prestação de serviços nos parques nacionais são basicamente a Lei ${ }^{\circ}$ 8.666, de 21 de junho de 1993 (Lei de Licitações), a já citada Lei no 8.987, de 13 de fevereiro de 1995 (Lei das Concessões) e a Lei 11.079, de 30 de dezembro de 2004 (Lei das Parcerias Público-Privadas - PPP).

As opções entre as modalidades de delegação de prestação de serviços públicos são influenciadas pelas diferentes formas de conceber o Estado e a sua atuação nas esferas pública e privada. Ao mesmo tempo em que 
não se quer mais o Estado como prestador de serviço, quer-se o Estado que estimule e que subsidie a iniciativa privada, quer-se a colaboração entre público e privado na realização de atividades administrativas do Estado (DI PIETRO, 2005). No entanto, quer-se também o Estado que assegure os direitos difusos e coletivos, que seja capaz de prestar o serviço público adequado e de harmonizar os diversos interesses relacionados ao acesso dos espaços e recursos naturais de uso comum.

A parceria entre os setores público e privado pode ser entendida em sentido amplo para abranger as várias modalidades de ajustes para a consecução de objetivos comuns (DI PIETRO, 2005, p. 21). Independentemente do tipo de ajuste escolhido (concessão, permissão, autorização, parceria público-privada, parceria com organizações da sociedade $\mathrm{civil}^{2}$ ), os princípios que orientam a prestação de serviço público adequado, já citados acima, aportam reflexões constantes sobre o papel dos atores públicos e privados.

A compreensão sobre as diferentes modalidades de prestação de serviços e de suas respectivas características importa para planejar a gestão da visitação num determinado parque. Devem ser considerados aspectos como: envergadura econômica do serviço e/ou empreendimento, número total de usuários, arrecadação bruta estimada do serviço prestado, originalidade do tipo de serviço na área, oferta do serviço em escala regional (RODRIGUES, 2009).

Conforme destaca Justen Filho (2006), as modalidades de delegação para a prestação de serviços são instrumentos de implementação de políticas públicas. Não são meramente mecanismos para formalizar a parceria com a iniciativa privada ou como uma manifestação da atividade administrativa contratual do Estado. São oportunidades para a realização de valores constitucionais fundamentais, como cidadania, participação, equidade.

Além desses valores, serão abordados no próximo item os aspectos socioeconômicos que influenciam a escolha da modalidade e a dinâmica de prestação de serviços de apoio à visitação nos parques nacionais.

\section{Aspectos socioeconômicos da prestação de serviços de apoio à visitação em unidades de conservação}

Em termos gerais, destacam-se os seguintes aspectos socioeconômicos que permeiam a discussão sobre a prestação de serviços de apoio à visitação em parques nacionais:

a) a remuneração pela prestação de serviços deve assegurar o equilíbrio econômico-financeiro dos contratos firmados com particulares;

b) a receita obtida com a prestação de serviços pode incrementar os recursos para a gestão dos parques nacionais;

c) a gestão da visitação deve propiciar o acesso ao serviço adequado (qualidade, preços acessíveis, segurança, etc.);

d) o efeito multiplicador da prestação de serviços de apoio à visitação nos parques nacionais pode dinamizar a economia e favorecer o desenvolvimento socioeconômico local.

Todos estes aspectos estão interligados. Um dos principais elos entre eles é a viabilidade econômica da prestação de serviços. Assim, o estudo de viabilidade econômica, que precede a exploração comercial de um determinado serviço, deve subsidiar o órgão gestor do parque nacional na definição de preços compatíveis com o serviço prestado, no desenho dos possíveis cenários para o alcance do equilíbrio econômico-financeiro, na escolha da modalidade de delegação mais adequada para a prestação de serviço ou uso de bem público, considerando a capacidade de suporte da área e os potenciais efeitos socioeconômicos em escala local (RODRIGUES, 2009).

O equilíbrio econômico-financeiro na prestação de serviços e no uso de bem público é um dos critérios reguladores dos contratos. Quando se trata de concessão de serviços, é fundamental a definição de mecanismos para manter o equilíbrio entre os encargos do concessionário e a remuneração a ser paga via tarifas cobradas

\footnotetext{
${ }^{2} \mathrm{O}$ art. 30 da Lei 9.985, de 2000, regulamentado pelos arts. 21 a 24 do Decreto 4.340, de 2002, autoriza a gestão compartilhada entre o órgão gestor da unidade de conservação e organizações da sociedade civil de interesse público, as OSCIP, mediante a assinatura de um termo de parceria nos termos da Lei 9.790 , de 23 de março de 1999 .
} 
dos usuários. Além disso, como citado acima, a viabilidade econômica do empreendimento ou serviço é fator crucial para atrair investimentos da iniciativa privada (BANDEIRA DE MELLO, 2004; DI PIETRO, 2005).

Esse processo, que se caracteriza pelo desafio de harmonizar a prestação de serviço adequado e a sua viabilidade econômica, pode acarretar uma tensão de interesses entre as esferas pública e privada. Pereira (2003) ressalta a finalidade do Estado na realização do bem comum, a qual não se baseia no lucro, mas na prestação de serviço público por meio de tarifas com valores módicos. Por outro lado, o ente privado busca obter ganhos e a justa remuneração pelo serviço que realiza. Segundo ele:

Dois são, portanto, os agentes envolvidos: o poder público e o concessionário. O primeiro preocupa-se com a qualidade, a continuidade e o atendimento adequados dos serviços oferecidos à população, devendo, para cumprir tal desiderato, editar regras justas e claras, em procedimentos transparentes, assegurando a indispensável legitimidade à concessão. O segundo interessa-se pela lucratividade decorrente da execução do serviço, embora resignado ao dever de respeitar suas obrigações contratuais (PEREIRA, 2003, p. 32).

A tensão de interesses é vista por alguns autores como complementaridade ou identidade de interesses. Justen Filho (2006), por exemplo, argumenta que a prestação de serviço público adequado e satisfatório é um objetivo comum, compartilhado pelo Estado, pela sociedade civil e pelo concessionário. Nesta perspectiva, a concessão seria um meio para obter a colaboração dos particulares no desempenho dos serviços públicos. Para ele, "o concessionário não é um inimigo da administração", pois acredita que o fato de o concessionário ser um empresário privado não quer dizer que ele estará preponderantemente orientado pelo lucro (2006, p. 511).

Nesta linha, Eagles et al. (2002) salientam que os papéis desempenhados pelas esferas pública e privada no desenvolvimento do turismo em áreas protegidas podem ser ao mesmo tempo cooperativos e conflitantes.

De qualquer modo, os contratos para a prestação de serviços de apoio à visitação ou uso de bem público devem respeitar a legislação de regência, os objetivos do parque nacional, seus instrumentos de planejamento (plano de manejo, plano de uso público) e outros regulamentos específicos que visem proteger as unidades de conservação contra uso predatório. Por outro lado, o órgão gestor da unidade de conservação deve apresentar os possíveis cenários de retorno do capital investido pelo prestador de serviço, por meio de uma equação econômico-financeira justa para ambas as partes (ROCKTAESCHEL, 2006).

A tensão de interesses, caso não ocorra o desempenho adequado por parte do concessionário e a fiscalização por parte do Estado, pode conduzir a duas situações particulares (PEREIRA, 2003). Para que a concessão seja vantajosa para o ente privado, o investidor pode optar por vender o seu produto na escala suficiente para obter o lucro desejado ou aumentar o preço do serviço de modo a viabilizar o lucro por meio de uma quantidade reduzida de produto comercializado.

A primeira opção pode ocasionar uma sobrecarga de visitantes, comprometendo a integridade dos recursos naturais e culturais. Ela tensionaria a capacidade de suporte da atividade, podendo infringir normas ambientais. A segunda pode limitar o acesso por meio do aumento do preço dos ingressos ou de outros valores pagos para a utilização dos serviços de apoio à visitação.

Deve-se lembrar que quando o volume de acesso for limitado em função de critérios ambientais, o papel do setor público seria garantir que esse processo fosse, sempre que possível, equitativo (MORE e MANNING, 2004).

No que diz respeito à definição dos valores a serem pagos pelos usuários para utilização dos serviços, que se reflete na remuneração da concessionária, é oportuno destacar a análise de Meirelles (2000):

\footnotetext{
O serviço concedido deve ser remunerado por tarifa (preço público) e não por taxa (tributo). A tarifa deve permitir a justa remuneração do capital, o melhoramento e a expansão do serviço, assegurando o equilíbrio econômico e financeiro do contrato. Daí porque se impõe a revisão periódica das tarifas, de modo a adequá-las ao custo operacional e ao preço dos equipamentos necessários à manutenção e expansão do serviço. A revisão das tarifas é ato privativo do poder concedente, em negociação com o concessionário, que deverá demonstrar a renda
} 
da empresa, as despesas do serviço e a remuneração do capital investido ou a ser investido nas ampliações necessárias (MEIRELLES, 2000, p.362).

A Lei de Concessões abre a possibilidade de o concessionário prever fontes de receitas alternativas, complementares, acessórias ou de projetos associados, no atendimento às peculiaridades de cada serviço público. Essa regra, de acordo com Azevedo e Alencar (1998), deve ser utilizada com o objetivo de possibilitar a cobrança de tarifas módicas, beneficiando o usuário do serviço e abrindo oportunidades de outras fontes de receita para o concessionário, além do preço cobrado pelo serviço.

No caso dos serviços de apoio à visitação nos parques nacionais, essa dinâmica pode ser interessante para incrementar os serviços prestados (aluguel de equipamentos, contratação de guias). No entanto, pode encarecer a visita ao condicionar a realização de uma determinada atividade a gastos extras por parte dos usuários.

Para evitar distorções, acredita-se que o desenho da concessão deveria prever o oferecimento da infraestrutura e os equipamentos básicos para a utilização de um determinado serviço e possibilitar que, eventualmente, outros serviços possam ser oferecidos, de forma adicional. Essa complementaridade possibilitaria a geração de outras fontes de receita ao prestador de serviço, não gerando, necessariamente, mais ônus aos usuários.

$\mathrm{O}$ princípio da modicidade das tarifas, vinculado à isonomia, obriga os prestadores de serviços a fixarem as tarifas de acordo com parâmetros que permitam alcançar o maior número possível de usuários. Furtado (2007) entende que:

A adoção do princípio da modicidade tarifária importa em que não seja observada a lógica do mercado na fixação do preço a ser cobrado do usuário. De acordo com parâmetros da microeconomia, o preço do produto ou do serviço deve ser fixado de modo a maximizar o lucro do empresário, e não necessariamente de modo a alcançar o maior número possível de usuários. [...] cumpre ao poder concedente indicar os valores máximos e, quando possível, admitir mecanismos de competição de modo a forçar os prestadores do serviço a reduzir as tarifas cobradas (FURTADO, 2007, p. 718).
Por um lado, conforme orienta Furtado (2007), a lógica utilizada na prestação de serviços públicos não deve estar pautada no mercado, mas sim em parâmetros sociais e de renda que subsidiem o estabelecimento de preços módicos, acessíveis aos usuários. Porém, quais parâmetros o Estado deve utilizar para definir o valor máximo para um serviço que é, em grande medida, orientado pela lógica de mercado, como no caso dos serviços e das atividades de apoio à visitação nos parques nacionais?

A prestação destes serviços requer a adoção de equipamentos e técnicas que promovam a qualidade, a segurança e o menor impacto ambiental durante a realização das atividades. Para tanto, é necessário que o prestador de serviço invista no seu empreendimento para propiciar o atendimento dos requisitos necessários ao desenvolvimento da atividade, podendo ocasionar um aumento no preço cobrado dos visitantes.

Isso não significa, no entanto, que o processo de agregação de valor ao serviço prestado dentro de um parque nacional deva estar pautado prioritariamente nos preceitos da esfera privada. Por se tratar de um parque nacional, área sujeita a regime de interesse público, a exploração comercial de serviços deve se basear em um conjunto de critérios e princípios que busquem o equilíbrio econômico-financeiro do contrato de concessão, a definição de valores condizentes com o serviço prestado e, de maneira mais ampla, o alcance dos objetivos de sua criação.

No entendimento de Justen Filho (2006), a modicidade tarifária pode afetar a própria decisão quanto à concepção do serviço público, pois o grau de sofisticação do serviço pode tornar inviável a sua fruição por parte dos usuários. No caso dos serviços de apoio à visitação nos parques nacionais, de caráter comercial, a aplicação do princípio da modicidade pode estar atrelada ao fato de o Estado buscar um equilíbrio entre as opções de serviços disponibilizadas aos visitantes.

Isso indica que as opções de serviços devem atender a grupos com diferentes padrões aquisitivos. Neste sentido, os parques nacionais podem propiciar diversas alternativas de apoio à visitação e não necessariamente apenas um conjunto de serviços com um alto padrão de sofisticação (e preços compatíveis), favorecendo apenas uma parcela da sociedade. 
Azevedo e Alencar (1998) citam situações que podem servir como exemplos para os serviços prestados nos parques nacionais. O primeiro exemplo são os ônibus executivos, que prestam serviço de transporte com equipamentos sofisticados e que favorecem o conforto do usuário.

Outro é o estabelecimento de tarifas diferenciadas em horários, dias ou períodos específicos. O alto fluxo de usuários num determinado período requer que o concessionário tome cuidados especiais (contratação de pessoal, gastos extras com limpeza, energia, etc.) que podem onerar os custos de sua operação. Por outro lado, em períodos de baixa movimentação, o concessionário pode oferecer tarifas mais baixas para estimular a utilização do serviço.

Furtado (2007) argumenta que a adoção de um modelo de concessão que reduza o risco do concessionário é uma decisão de política estratégica do Estado, que não conflita com o sistema jurídico. Segundo o autor, "cabe ao edital de concessão definir as garantias de equilíbrio do contrato. Não encontramos em nosso ordenamento jurídico qualquer empecilho à adoção de garantias ou de modelo que objetive a redução dos riscos do investimento" (p. 565). Furtado entende que o sucesso de uma concessão está diretamente relacionado ao modelo de recomposição do equilíbrio do contrato, o qual requer o detalhado exame dos riscos do empreendimento.

Ainda com base na análise de Furtado (2007), cumpre destacar a crítica sobre os interesses envolvidos na concessão e a diferença entre os contratos comuns para a prestação de serviços, regidos pela Lei de Licitações, e os contratos de concessão. Na concessão, o contratado não é mero prestador de serviço (como ocorre nos “contratos comuns"), pois ele é um investidor que irá avaliar o custo de oportunidade do investimento proposto na concessão. Portanto, o investidor irá desenhar uma proposta que seja capaz de otimizar o investimento, por meio da combinação do capital próprio com o capital de terceiros. "Este é o escopo básico do concessionário: o maior retorno possível para o capital investido" (p. 547).

Contudo, deve-se lembrar que não é apenas o interesse do prestador de serviço que está em jogo. $\mathrm{O}$ Estado e os usuários dos serviços são peças fundamentais para completar a equação. Os três atores têm interesses diferentes e legítimos que devem ser equalizados na prestação dos serviços.

\section{Os potenciais efeitos econômicos no âmbito da atuação pública e privada}

Ao analisar os critérios para o julgamento da licitação, indicados na Lei de Concessões, Furtado (2007) constatou uma tendência de estimular a busca pela vantagem econômica por parte do Estado, pois se admite a escolha da proposta que oferecer "a maior oferta, nos casos de pagamento ao poder concedente, pela outorga da concessão". Ao possibilitar a escolha apenas deste critério, a lei estaria distorcendo os interesses envolvidos no sistema de concessão de serviço público, pois, conforme argumenta Furtado (2007):

É inadmissível que o poder público queira utilizar a concessão como instrumento para obtenção de receitas. O seu interesse, aquele que motiva a existência do modelo de concessão adotado no Brasil, deve ser a prestação do serviço adequado aos usuários. Este corresponde ao interesse público primário do sistema de concessão. Admitir que o concessionário deve pagar ao poder concedente pela realização do contrato de concessão importa, necessariamente, em onerar o usuário, que tem direito à prestação do serviço adequado, o que pressupõe a modicidade de tarifa (FURTADO, 2007, p. 548).

Embora os argumentos do autor sejam plausíveis, ele mesmo aponta as contradições e dúvidas recorrentes relacionadas, em grande medida, à utilização de conceitos jurídicos indeterminados, como lucro justo, modicidade tarifária, risco do investimento. Com relação ao lucro justo, por exemplo, o autor considera descabida a introdução de parâmetros éticos, inerentes ao conceito de justiça, na avaliação do lucro, conceito estritamente econômico. Ao invés de lucro justo, entende que seria melhor buscar o lucro adequado ou admissível, que seria definido pelo custo de oportunidade.

Furtado sustenta que todos os atores envolvidos (Estado, concessionário, usuário) têm um objetivo comum, que é a prestação de um serviço de boa qualidade. Assim, o lucro almejado pelo investidor é legítimo, na medida em que o empreendimento atende aos padrões de qualidade e ainda gera lucro para compensar o investimento realizado. No entanto, deslegitima a busca pela vantagem econômica por parte do Estado (p. 549). 
More e Manning (2004), ao discutir a função pública de parques nacionais em países como Estados Unidos e Canadá, chamam a atenção para o fato de que a ênfase na eficiência econômica na gestão destas áreas pode engendrar uma perspectiva excludente, que acaba "transferindo os benefícios dos parques nacionais das classes média e baixa em direção à elite" (p. 297).

Contudo, ao mesmo tempo em que o uso público pode gerar receitas com os ingressos de visitação e os valores pagos pelas concessões, gera despesas com o manejo dos impactos, a manutenção de infraestrutura, os serviços de vigilância e portaria para cobrança de ingressos, entre outras ${ }^{3}$. Neste contexto, os recursos provenientes da visitação deveriam exceder os seus custos, para que efetivamente gerem benefícios para as áreas protegidas, ao invés de as áreas protegidas simplesmente subsidiarem esta atividade (FONT, COCHRANE e TAPPER, 2004).

As experiências internacionais sinalizam que a gestão dos parques nacionais está fortemente orientada pelo turismo, mais precisamente pela possibilidade de estimular uma alternativa de geração de renda para o manejo destas áreas. Nesta dinâmica, os parques nacionais passam a ser geridos com o objetivo principal de atrair turistas (BRANDON, 1998).

Este autor chama a atenção para o fato de as políticas de áreas protegidas perderem o sentido do que realmente devem fazer com os parques nacionais, visto que sofrem pressões de diversos setores econômicos intensivos na utilização da natureza (mineração, exploração madeireira, rodovias). Esta pressão favorece a distorção na missão dos parques, que são manejados como "áreas de praia que atraem dinheiro de turistas", ao invés de priorizar a conservação da natureza (BRANDON, 1998, p. 419).

A disputa com outros setores da economia (setor agrícola, setor energético, setor industrial, setor minerário) engendrou uma ampla discussão (e especulação) sobre a precificação dos serviços ambientais prestados pelas unidades de conservação (ou melhor, pela natureza que se encontra circunscrita a estas áreas). Neste debate, acredita-se que os formuladores e implementadores de políticas ambientais devam ser capazes de conquistar adeptos à sua causa, sendo o mercado um de seus principais aliados. Esta linha defende que esses atores se dediquem a um novo ramo do conhecimento relacionado ao mercado e aos "negócios da natureza".

Em 2007, o Grupo de Trabalho para Áreas Protegidas, instituído no âmbito da Convenção sobre Diversidade Biológica (CDB), elaborou um documento com diretrizes para mobilizar diferentes alternativas para o financiamento do programa de trabalho para as áreas protegidas construído no âmbito da Convenção ${ }^{4}$. $\mathrm{O}$ documento explorou mecanismos inovadores para desenvolver as parcerias público-privadas ${ }^{5}$ como um dos instrumentos mais promissores para o financiamento do referido programa.

Umas das referências para a construção desse documento foi um artigo intitulado "Managing National Parks - how public-private partnerships can aid conservation?" (SAPORITI, 2006). Publicado no âmbito do fórum View Point (Public Policies Journal), é uma iniciativa que visa disseminar políticas públicas para que o setor privado promova soluções para o desenvolvimento baseadas no mercado (market-based solutions). O artigo ressalta que a comercialização responsável (responsible commercialization) por meio de parcerias entre o setor público e o setor privado pode proporcionar uma importante alternativa para a conservação das áreas protegidas.

Algumas experiências desenvolvidas na África do Sul mostraram que estas parcerias podem incrementar os serviços por meio da administração profissional e do marketing, reduzir a dependência de subsídios públicos e mobilizar capital para investimento na infraestrutura dos parques e na conservação da biodiversidade.

As parcerias podem se dar de duas formas: "parcerias tradicionais no turismo, nas quais o setor privado utiliza a propriedade pública" para promover serviços

\footnotetext{
${ }^{3}$ Passold e Kinker (2005), ao analisar o manejo da visitação no Parque Nacional do Iguaçu, concluem que quanto mais uma UC arrecada por meio da visitação, mais irá gastar em manejo, manutenção, investimentos necessários, etc., sendo que este recurso deve ser viabilizado de modo a manter a qualidade da visita.

4 "Exploration of options for mobilizing, as a matter of urgency, through different mechanisms adequate and timely financial resources for the implementation of the Programme of Work on Protected Areas" - UNEP/CBD/WG-PA/2/4, 29 de novembro de 2007.

${ }^{5}$ É importante ressaltar que nesse trecho não estamos nos referindo necessariamente à modalidade de concessão de serviços prevista na Lei 11.079, de 2004, já referida nesse artigo.
} 
e gerar rendimentos por meio de serviços de alimentação, hospedagem, lojas de souvenirs e "parcerias para o manejo da biodiversidade, nas quais o setor privado representa uma função pública em nome do governo, como a conservação dos bens naturais públicos localizados nas áreas protegidas" (SAPORITI, 2006, p. 1).

A opção de se utilizar um ou outro modelo depende basicamente da capacidade técnica e administrativa das instituições públicas responsáveis pelos parques nacionais. A primeira opção são as tradicionais concessões realizadas para a prestação de serviços de apoio à visitação. A segunda opção apresenta parcerias para administrar e financiar as áreas protegidas, incluindo funções como proteção, fiscalização e manutenção de infraestrutura mínima.

Em 2003, a fundação African Parks, administrada por wealthy conservacionistas, assinou seis contratos de concessão em cinco países da África (Etiópia, Malawi, Sudão, Zâmbia e República do Congo), com prazos de validade variando entre cinco e 30 anos. Esta fundação atua em países que ainda estão "na fronteira da indústria do turismo" e cujas áreas protegidas pelas quais assumiu a responsabilidade foram, durante muito tempo, negligenciadas, exploradas de maneira descontrolada e destruídas em virtude da guerra e da fome. Para tornar os parques economicamente viáveis, a African Parks investiu em grande medida na restauração da flora e da fauna, pois "sem o retorno dos grandes mamíferos, os turistas também não voltam". Estas experiências são encaradas como uma forma de comercialização responsável dos parques nacionais, pois oferecem uma maneira de capturar o seu significativo valor econômico e podem gerar recursos suficientes para cobrir os seus custos de operação e manutenção (SAPORITI, 2006, p. 3).

Seguindo a tendência dos parques nacionais africanos, o Brasil recentemente começou a estimular que empresas privadas "adotem" parques nacionais e estaduais brasileiros. Em 2011, foi divulgada a assinatura de um contrato entre as empresas MGX e OGX (Grupo EBX), que atuam nos setores de mineração, logística, petróleo, e o Funbio, para a adoção, até 2018, dos Parques Nacionais Marinho de Fernando de Noronha (PE) e Lençóis Maranhenses (MA). Serão investidos cerca de 7,8 milhões de reais em obras de estrutura, compra de bens e contratação de serviços para apoiar física, logística e financeiramente a gestão dessas áreas (FUNBIO, 2012) ${ }^{6}$.

Para o Grupo EBX, a parceria com o Instituto Chico Mendes de Conservação da Biodiversidade (ICMBio) integra as iniciativas da "Política de Sustentabilidade" de suas empresas ${ }^{7}$. Para o Ministério do Meio Ambiente e o ICMBio, a adoção é uma oportunidade para investimentos de longo prazo nos parques nacionais.

Contudo, conforme destacado no depoimento do ex-Ministro do Meio Ambiente, Carlos Minc, a política de apoio das empresas para a proteção das unidades de conservação não deve ser utilizada como uma forma de aliviar seus problemas ambientais: "Qualquer grande empresa pode bater no peito e dizer que está ajudando na preservação, na manutenção e no bom uso de áreas da grandiosidade, da beleza cênica e da diversidade biológica de Noronha, Lençóis e Pantanal".

O ministro acrescentou que espera "que outros empresários se mirem nesse exemplo", mas ressaltou que doações como essas não resolvem problemas relativos a passivos ambientais das empresas. "Doações não resolvem os problemas de mitigação, compensação, pendências e multas das empresas. Também não facilitam processos de licenciamento". 8

A iniciativa do Ministério do Meio Ambiente motivou a crítica de ambientalistas, que salientam a necessidade de o Estado assumir a responsabilidade pelas áreas protegidas:

Todo mundo concorda com o fato de ser desejável que o setor privado participe mais ativamente na preservação da natureza, mas para isso existem as reservas particulares do patrimônio natural e toda doação ou apoio do setor privado para as unidades de conservação públicas será muito bem recebido. Porém não a sua pretensa "entrega para adoção". [...]. Claro está que muitas das atividades

\footnotetext{
${ }^{6}$ Disponível em: <http://www.funbio.org.br/o-que-fazemos/projetos/adocao-de-parques>. Acesso em: 03/082013.

${ }^{7}$ Para maiores informações sobre a Política de Sustentabilidade do Grupo EBX, consultar: <http://www.ebx.com.br/pt-br/grupo-ebx/Documents/EBX_12-06.pdf>.

${ }^{8}$ Reportagem divulgada na página eletrônica do Ministério do Meio Ambiente no dia 14 de outubro de 2008. Disponível em: <www.mma.gov.br>. Acesso em: $23 / 11 / 2008$.
} 
podem ser terceirizadas, como a recepção de visitantes, bares, lanchonetes, restaurantes, camping, coisas usuais em qualquer sistema de unidades de conservação bem implantado em qualquer continente. Pode-se até fazer cogestão, que algumas vezes apresenta certo resultado [...] O que não pode o Poder Público fazer é delegar responsabilidades que lhes são inerentes pelo alcance social de seus fins (PÁDUA, 2008)9.

No caso brasileiro, ainda que a concessão dos serviços de apoio à visitação tenha sido influenciada por tendências administrativas que visam ampliar a atuação do setor privado na esfera pública, o manejo, a proteção e a fiscalização dos bens naturais inseridos nos parques nacionais continuam sendo atividades precípuas do poder público.

No que tange à gestão, o órgão gestor das unidades federais é responsável também por "promover e executar, em articulação com os demais órgãos e entidades envolvidos, programas recreacionais, de uso público e de ecoturismo nas unidades de conservação onde estas atividades sejam permitidas" (art. $1^{\circ}$, inciso V da Lei 11.516, de 28 de agosto de 2007). Assim, é desejável que essa atribuição seja desenvolvida em conjunto (parceria) com as empresas, comunidades locais e organizações da sociedade civil envolvidas na prestação de serviços de apoio à visitação nos parques nacionais e demais unidades de conservação.

Ainda no âmbito federal, o ICMBio e a Fundação SOS Mata Atlântica publicaram um termo de referência para contratação de pessoa jurídica para elaboração de "Estudo de Potencial de Captação de Recursos por meio da Adoção de Áreas e Patrocínio ao Parque Nacional da Tijuca". Dentre os objetivos do estudo estão a identificação de áreas com potencial para o estabelecimento de acordos de patrocínio e adoção e a valoração de áreas e monumentos para subsidiar o estabelecimento de acordos de adoção (patrocínio) com empresas e instituições públicas e privadas (ICMBio, 2013) ${ }^{10}$.
Outra iniciativa de "adoção" de unidades de conservação está em andamento no Estado do Rio de Janeiro. Em 2008, a mineradora Vale do Rio Doce adotou o Parque Estadual da Ilha Grande. Durante cinco anos, a empresa irá investir em recursos humanos, suprimentos, insumos e materiais necessários à operação do parque (JORNAL DO BRASIL, 2008) $^{11}$.

Assim, em função da carência de recursos humanos e financeiros para a gestão dos parques, a iniciativa privada tem passado a financiar uma parte significativa dos itens necessários para a gestão adequada dessas unidades de conservação. Despesas básicas com material de consumo, que deveriam ser garantidas pelo Estado como parte de suas responsabilidades em virtude da criação de uma unidade de conservação, acabam sendo incorporadas em contratos de "adoção" ou como contrapartida no âmbito de contratos de concessão.

\section{Os limites da dinâmica mercadológica no âmbito da gestão dos parques nacionais}

O Instituto Chico Mendes de Conservação da Biodiversidade tem o desafio de gerir e proteger a natureza inserida nos parques nacionais (áreas públicas) e requer condições mínimas para tanto. A iniciativa privada dispõe de recursos e habilidade para responder às demandas dos consumidores e desenvolver novos produtos, que podem aumentar os recursos para a manutenção de seus negócios e também do próprio parque.

Quando o assunto é a operação turística em parques nacionais, a experiência da iniciativa privada é encarada pelos potenciais apoiadores como "um diferencial em relação aos administradores públicos que, em geral, são inexperientes nesse campo" (GORINI, MENDES e CARVALHO, 2006, p. 185).

Kramer et al. (2002) acreditam que uma vantagem da parceria com o setor privado é que ele "pode ser mais bem-sucedido que o setor público em providenciar os

\footnotetext{
${ }^{9}$ Disponível em: <http://www.oeco.org.br/maria-tereza-jorge-padua/19250-minc-e-o-leilao-de-parques-nacionais >. Acesso em: 18/11/2008.

${ }^{10}$ Informação divulgada na página do Instituto Chico Mendes de Conservação da Biodiversidade (ICMBio) no dia 2 de abril de 2013 . Disponível em: <www. icmbio.gov.br>.

${ }^{11}$ Disponível em: <http://www.jb.com.br/rio/noticias/2008/12/05/vale-adota-parque-estadual-da-ilha-grande/>. Acesso em: 10/04/2009.
} 
especialistas em mercado, necessários para competir no mercado internacional altamente competitivo da indústria do turismo de natureza" (p. 363).

A valorização da expertise da iniciativa privada gerou algumas mudanças no setor público, que se tornou mais business-like ao desenvolver planos de negócio, sistemas de arrecadação e parcerias com a iniciativa privada (MORE e MANNING, 2004, p. 294). Esta lógica induz que os formuladores e implementadores das políticas de áreas protegidas assumam um novo papel. Porém, qual é o limite do "saber mercadológico" destes atores? Qual é o limite da precificação e da mercantilização da natureza em áreas de domínio público, como os parques nacionais? De que forma os órgãos públicos responsáveis pelo manejo dos parques devem participar da produção econômica vinculada aos serviços ambientais?

O desenho de uma concessão em um parque nacional, conforme apresentado, requer a compreensão e a consideração de aspectos socioeconômicos que vão além da definição do objeto e/ou da atividade a ser concedida no plano de manejo da unidade. Um dos principais elementos na elaboração do estudo de viabilidade econômica para exploração de um serviço é o funcionamento do mercado no qual está inserido.

As relações de mercado envolvem todos os estágios de produção de uma mercadoria, da identificação de uma demanda até a sua produção para o consumo. Derani (2002) argumenta que o mercado se configura a partir de um conjunto de relações econômicas resultantes dos investimentos privados, com a finalidade de obter lucro. Portanto, explica a autora, a confrontação entre serviço público e atividade privada, embora não estejam em competição, gera um impasse, posto que a lógica do mercado é distinta da lógica do serviço público.

Enquanto que a lógica do mercado se insere na preferência individual para produção e consumo no poder econômico que detêm estes indivíduos para exercer a sua preferência, a lógica do serviço público é a de produção para atingir necessidades sociais. "A primeira se reproduz pela movimentação de valores de troca, a segunda dirige-se à produção de valores de uso social". Neste contexto, a característica "pública" do serviço, mesmo quando executada pelo setor privado, demanda uma regulação diferenciada da atividade econômica por parte do Estado, com vistas à satisfação do interesse coletivo (DERANI, 2002, p. 75 e 89) ${ }^{12}$.

A concessão de serviços implica uma ampliação da atividade normativa do Estado, pois, quanto mais complexa for a atividade concedida, quanto mais abrangentes e fundamentais forem os serviços entregues à atividade privada, maior será a necessidade de funcionários altamente qualificados e vinculados a um amplo leque de deveres normatizados (DERANI, 2002).

O processo de concessão implica um aumento da regulamentação e do aparelhamento do estado, e não uma retirada do Estado e diminuição da "inflação legislativa". Se o processo de aumento de concessão dos serviços não é acompanhado por este crescimento do Estado, verifica-se imediatamente a substituição do interesse público pelo interesse privado e a eficiência do setor público se torna eficiência privada de alocação e aumento do rendimento (DERANI, 2002, p. 94).

A análise de Derani (2002) guarda estreita relação com o caso da concessão de serviços de apoio à visitação em parques nacionais. Nestas áreas, a concessão de serviços pode propiciar a qualificação da visita por meio de serviços, funcionários e equipamentos especializados. Contudo, isso não significa que o órgão responsável pela área irá direcionar menos esforços para o manejo da visitação, pois terá que monitorar os serviços prestados, considerando os critérios ambientais (mínimo impacto), econômicos (tarifas justas e equilíbrio econômico-financeiro) e sociais (inserção de atores locais e satisfação do visitante).

A viabilidade econômica dos serviços e das atividades de apoio à visitação depende em grande medida de fatores externos à gestão da visitação no parque. Esses fatores estão relacionados à dinâmica do turismo em suas áreas de influência, isto é, nos municípios e nas

\footnotetext{
${ }^{12}$ Derani (2002) analisa que: "Dependendo do modo como são formados, geridos e fiscalizados os contratos de concessão ou autorização de serviço público, o serviço prestado tende à incapacidade de gerar externalidade pública. Pela concepção material do conceito de Serviço Público, este serviço deixa de ser público na medida em que não é mais tratado como público, independentemente do que formalmente se disponha sobre ele. Nesta desconexão entre previsão normativa de destinação pública do serviço e a realidade da incapacidade de gerar benefícios à coletividade, constata-se a ilegalidade ou inconstitucionalidade da atividade" (p. 87).
} 
regiões que apresentam parques nacionais. A frequência de turistas a uma determinada área depende das condições de acesso, da infraestrutura de hospedagem e de alimentação, da promoção turística, da diversidade de atrativos, entre outros aspectos. Tais aspectos influenciam a procura por determinado destino turístico e, consequentemente, a demanda pelos serviços de apoio ao turismo.

De acordo com informações do ICMBio, em 2012, apenas dois parques nacionais brasileiros recebem acima de 1,5 milhão de visitantes/ano. Os Parques Nacionais de Iguaçu (PR) e da Tijuca (RJ) recebem juntos cerca de 4 milhões de visitantes $/$ ano $^{13}$. No caso do Parque Nacional do Iguaçu, o alto fluxo de visitantes, em comparação com todos os demais parques nacionais, é uma das principais justificativas para a consolidação de serviços compatíveis com essa demanda.

Assim, o porte dos investimentos e das estruturas deve ser proporcional à demanda e aos impactos relacionados ao turismo no parque. Neste caso, o escopo da prestação de serviços no parque prioriza empresas que tenham capacidade de investimento e, ao mesmo tempo, obtenham o retorno do capital despendido.

O Parque Nacional do Iguaçu tem sete empresas concessionárias e atualmente estão sendo executados novos contratos de concessão, como o do Hotel das Cataratas. O novo concessionário irá reformar o hotel e promover investimentos em algumas estruturas de apoio à visitação, como a implantação de ciclotrilha e reforma do portão de entrada do parque (MMA, 2008).

Contudo, como deve ser desenhada a prestação de serviços em parques nacionais que apresentam um fluxo médio e/ou pequeno de visitantes? Um parque com uma visitação anual de 30 mil visitantes é um destino "atraente" em termos de investimentos por parte da iniciativa privada? Quais são as especificidades entre os modelos de prestação de serviços em termos de desenvolvimento socioeconômico local?

A atratividade para o investidor está relacionada ao retorno econômico que ele poderá obter, dentro do menor prazo possível e com o maior grau de confiabilidade. Esse retorno pode estar associado ao número de clientes (usuários) interessados em acessar o serviço e à tarifa cobrada para a sua utilização, ou a ambos. Contudo, em se tratando de áreas legalmente instituídas para a conservação da natureza, como os parques nacionais, a dinâmica de visitação é orientada prioritariamente por estratégias de manejo compatíveis com esse objetivo.

Assim, quando o assunto é a concessão de serviços de apoio à visitação, os elementos relacionados ao mercado turístico (demanda, competitividade, lucro) entram em cena e, caso não sejam devidamente planejados, podem distorcer a função dos parques nacionais.

Nesse ponto, emerge a discussão sobre a ética que orienta o processo de prestação de serviços nos parque nacionais. Isso se coloca tanto em termos ambientais, que trazem à tona a questão da supremacia do mercado frente à conservação da natureza, quanto em termos socioeconômicos, que dizem respeito aos arranjos institucionais que possibilitem a inserção dos atores locais no processo de prestação de serviços.

$\mathrm{O}$ efeito multiplicador do turismo em termos de geração de emprego e renda é um dos fatores mais salientados no âmbito da discussão sobre o papel dos parques nacionais no desenvolvimento regional. Mas é necessário qualificar os indicadores de emprego e renda visando a uma análise mais aprofundada sobre os benefícios e as melhorias na qualidade de vida das populações locais. As iniciativas de micro e pequeno porte, por exemplo, tendem a possibilitar uma maior participação das comunidades locais na prestação de serviços de apoio à visitação, pois permitem uma composição com reduzido investimento e com base em insumos locais. Além disso, essas iniciativas favorecem a liderança por parte das comunidades e podem atender à demanda em parques nacionais com um menor fluxo de visitantes (RODRIGUES, 2009).

\section{Considerações finais}

A carência de recursos humanos e financeiros é um fato recorrente na rotina de gestão das unidades de conservação, ainda mais quando se trata de implementar e qualificar a infraestrutura de apoio à visitação. Assim, dependendo do formato e da viabilidade econômica da

${ }^{13}$ Informação fornecida pela Coordenação Geral de Uso Público do Instituto Chico Mendes de Conservação da Biodiversidade em abril de 2012. 
concessão, é necessária a consolidação de equipamentos e infraestrutura com recursos injetados pelo próprio concessionário.

Alguns exemplos recentes nos parques nacionais no Brasil e em outros países demonstram que a iniciativa privada está financiando ações que vão além das estruturas de apoio à visitação, contemplando itens necessários para apoiar a manutenção e a proteção da unidade. Neste contexto, o aporte de recursos humanos e financeiros por parte das organizações pública e privada requer uma análise criteriosa, considerando as funções e as responsabilidades no âmbito da gestão dos parques nacionais. Assim, a prestação de serviços de apoio ao uso público demanda uma composição de diversas alternativas financeiras, especialmente de fontes orçamentárias, para assegurar as condições básicas de gestão.

Um dos encargos atribuídos aos prestadores de serviços de apoio à visitação consiste no pagamento ao poder público de percentual sobre os rendimentos auferidos com as taxas cobradas dos visitantes. Esse aporte de recursos pode significar melhorias para a gestão dos parques nacionais. Contudo, os procedimentos para a aplicação destes recursos requerem estrito controle por parte das unidades de conservação que originaram a receita.

Além disso, o fluxo de aplicação da arrecadação deve ser amplamente divulgado para propiciar uma maior compreensão sobre os resultados gerados para a sociedade e para o parque nacional. Isso permite a todos os atores que participam da dinâmica de visitação nos parques nacionais acompanhar os efeitos dos recursos investidos.

Esse acompanhamento pode fortalecer o apoio público para a conservação da natureza, favorecendo o papel do visitante não apenas como um consumidor de serviços, mas como um cidadão com direitos e responsabilidades frente ao uso do espaço público.

\section{Referências}

AZEVEDO, E. de A.; ALENCAR, M. L. M. Concessão de serviços públicos: comentários às Leis 8.987 e 9.074 (Parte Geral), com as modificações introduzidas pela Lei 9648, de 27 de maio de 1998. São Paulo: Malheiros, 1998.

BANDEIRA DE MELLO, C. A. Curso de Direito Administrativo. 17. ed. São Paulo: Malheiros, 2004.
Em relação a este último aspecto, é certo que o Sistema Nacional de Unidades de Conservação requer a consolidação de fontes de receitas para a sua manutenção, mas a vantagem econômica almejada pelo Estado na prestação de serviços de apoio à visitação deve ser relativizada. A arrecadação obtida pelo poder público com as concessões e os ingressos pode incrementar os recursos para a manutenção e a gestão da própria visitação nas unidades de conservação e não simplesmente funcionar como a principal maneira de compensar a carência de recursos do orçamento público. Não se trata, portanto, de uma substituição do dever do próprio Estado de assegurar recursos financeiros para a infraestrutura mínima das unidades.

Assim, a viabilidade econômica, a capacidade de suporte e os preços acessíveis para o público são elementos que precisam estar sintonizados no âmbito da prestação de serviços de apoio à visitação. Esse é um desafio para os gestores dos parques nacionais, principalmente quando o saber mercadológico vinculado ao turismo invade a rotina destas áreas e se torna um dos principais elementos de apropriação da biodiversidade.

Por um lado, o Estado deve disponibilizar serviços de apoio ao uso público nos parques nacionais. Por outro, a esfera privada participa do processo como forma de possibilitar a prestação destes serviços de maneira adequada, compatível com os objetivos de criação destas áreas. Assim, a convivência entre os regimes público e privado no mesmo espaço, como é o caso da prestação de serviços de apoio à visitação em unidades de conservação, impõe o desafio constante na busca do equilíbrio entre os resultados econômico-financeiros privados e aqueles relativos à função pública de conservação da área e democratização do seu acesso.

BRANDON, K. Perils to parks: the social context of threats. In: _ _ REDFORD, K.; SANDERSON, S. E. Parks in peril: people, politics and protected areas. Washington (DC): Island Press and The Nature Conservancy, 1998. p. 415-440.

BRASIL. Lei 9.985, de 18 de julho de 2000. Regulamenta o art. $225, \S 1^{\circ}$, incisos I, II, III e VII da Constituição Federal, institui 
RODRIGUES, C. G. O.; GODOY, L. R. C. Atuação pública e privada na gestão de Unidades de Conservação: aspectos...

o Sistema Nacional de Unidades de Conservação da Natureza e dá outras providências. Brasília: DOU de 19/07/2000.

Decreto 4.340, de 22 de agosto de 2002. Regulamenta artigos da Lei n. ${ }^{\circ}$ 9.985, de 18 de julho de 2000, que dispõe sobre o Sistema Nacional de Unidades de Conservação da Natureza - SNUC, e dá outras providências. Brasília: DOU de 23/08/2002.

CETESB/SECRETARIA DO MEIO AMBIENTE DO ESTADO DE SÃO PAULO. Modelos de cogestão: discussão e propostas para o Estado de São Paulo. São Paulo: 2003. 200 p.

DERANI, C. Privatização e serviços públicos: as ações do Estado na produção econômica. São Paulo: Max Limonad, 2002.

DI PIETRO, M. S. Z. Parcerias na administração pública: concessão, permissão, franquia, terceirização, parceria público-privada e outras formas. 5. ed. São Paulo: Atlas, 2005.

EAGLES, P.; McCOOL, S.; HAYNES, C. D. Sustainable Tourism in Protected Areas: Guidelines for Planning and Management. IUCN, Gland, Switzerland and Cambridge, (UK), 2002.

FONT, X.; COCHRANE, J.; TAPPER, R. Pay per nature view: understanding tourism revenue for effective management plans. Leeds (UK): Leeds Metropolitan University. 2004. 47 p.

FURTADO, L. R. Curso de Direito Administrativo. Belo Horizonte: Fórum, 2007.

GORINI, A. P. F.; MENDES, E. F.; CARVALHO, D. M. P. Concessão de serviços e atrativos turísticos em áreas naturais protegidas: o caso do Parque Nacional do Iguaçu. Revista $B N D E S$, Rio de Janeiro: BNDES, Setorial 24, p. 171-209, set. 2006. Disponível em: $<$ http://www.bndespar.gov.br/conhecimento/bnset/set2406.pdf>. Acesso em: nov. 2006.

IBAMA/GTZ. Marco conceitual e diretrizes para terceirizações administrativas em unidades de conservação. Documento elaborado por ROCKTAESCHEL, B. M. M. Brasília, 1999.

JUSTEN FILHO, M. Curso de Direito Administrativo. São Paulo: Saraiva, 2006.

KRAMER, R. et al. O papel do setor privado no estabelecimento e manejo de áreas protegidas. In: TERBORGH, J.; SCHAIK,
C.; DAVENPORT, E.; RAO, M. (Orgs.). Tornando os parques eficientes: estratégias para a conservação da natureza nos trópicos. Curitiba: Editora UFPR/Fundação O Boticário de Proteção à Natureza, 2002. p. 363-380.

MEIRELLES, H. L. Direito Administrativo Brasileiro. 25. ed. São Paulo: Malheiros, 2000.

MINISTÉRIO DO MEIO AMBIENTE. Programa "Turismo nos Parques". Brasília: Ministério do Meio Ambiente, 2008.

MORE, T. A.; MANNING, R. E. The Public Function of Parks and Protected Areas. Working Papers of the Finnish Forest Research Institute 2.2004. Disponível em: <http:// www.metla.fi/julkaisut/workingpapers/2004/mwp002.htm>. Acesso em: jan. 2009.

PÁDUA, M. T. J. Minc e o leilão dos Parques Nacionais. 2008. Disponível em: <http://www.oeco.com.br>. Acesso em: 16/11/2008.

PASSOLD, A. J.; KINKER, S. S. Visitação como mecanismo para geração de recursos financeiros para o SNUC. Relatório preparado para o Fórum Nacional de Áreas Protegidas -2005. Brasília. Secretaria de Biodiversidade e Florestas / Ministério do Meio Ambiente. 36 p.

PEREIRA, E. S. B. A equação econômico-financeira da concessão de serviço público e o momento de sua formação. 2003. Disponível em: <http://www.cjf.gov.br/revista/numero23/ artigo06.pdf $>$. Acesso em: 22/06/2006.

ROCKTAESCHEL, B. M. M. M. Terceirização em áreas protegidas: estímulo ao ecoturismo no Brasil. São Paulo: Editora Senac, 2006.

RODRIGUES, C. G. O. O uso do público nos parques nacionais: a relação entre as esferas pública e privada na apropriação da biodiversidade. Brasília, Tese (Doutorado em Política e Gestão Ambiental) - Centro de Desenvolvimento Sustentável, Universidade de Brasília, 2009.

SAPORITI, N. Managing National Parks: How public-private partnerships can aid conservation. Public Policy for the Private Sector. Note Number 309. junho 2006. Disponível em: $<$ http://rru.worldbank.org/PublicPolicyJournal $>$. Acesso em: 20/08/2008. 